\title{
KAJIAN PEMODELAN DERET WAKTU: METODE VARIASI KALENDER YANG DIPENGARUHI OLEH EFEK VARIASI LIBURAN
}

\author{
Winda Triyani \\ Universitas Jenderal Soedirman \\ winda.triyani@gmail.com \\ Rina Reorita \\ Universitas Jenderal Soedirman \\ reo.rina@yahoo.com
}

\begin{abstract}
Calendar variation method is a technique that combines ARIMA modeling and regression modeling. Calendar variation is a cyclical pattern with varying periods due to the different calendar date position for each year. There are two types of calendar variation, trading day variation and holiday variation. In this research, modeling of time series with holiday variation was studied and modification of the modeling was developed for the case of holiday effect due to Eid's day occur. The case study was conducted to the data of train passenger number at DAOP V Purwokerto. It was found that the last model for the underlying data was the regression model with the residual following seasonal ARIMA $(1,1,1)(0,0,1)^{12}$ without constant parameter.
\end{abstract}

Keyword : time series, calendar variation, holiday variation, regression, ARIMA

\begin{abstract}
ABSTRAK. Metode variasi kalender merupakan teknik pemodelan yang mengkombinasikan model ARIMA dan model regresi. Variasi kalender merupakan pola berulang dengan panjang periode yang bervariasi akibat pengaruh penanggalan kalender yang berbeda-beda setiap tahunnya. Variasi kalender terdiri dari dua jenis yaitu variasi perdagangan dan variasi liburan. Pada penelitian ini, pemodelan deret waktu dengan variasi kalender yang dipengaruhi efek variasi liburan dipelajari dan dimodifikasi khususnya untuk efek liburan akibat hari Lebaran. Studi kasus pemodelan pada data jumlah penumpang kereta api DAOP V Purwokerto. Model variasi kalender yang diperoleh untuk data jumlah penumpang kereta api adalah model regresi dengan sisaan regresi yang berupa model musiman ARIMA $(1,1,1)(0,0,1)^{12}$ tanpa parameter konstanta.
\end{abstract}

Kata kunci : deret waktu, variasi kalender, variasi liburan, regresi, ARIMA

\section{PENDAHULUAN}

Banyak kegiatan ekonomi yang bergantung pada jumlah masing-masing hari tiap bulannya. Karena jumlah masing-masing hari berbeda-beda dari bulan ke bulan dan tahun ke tahun, maka deret waktu tersebut dapat dipengaruhi efek variasi kalender. Efek variasi yang disebabkan oleh banyaknya hari perdagangan 
tiap bulannya dinamakan efek variasi hari perdagangan (trading day variation). Selain variasi akibat perbedaan banyaknya hari perdagangan, beberapa hari libur yang waktunya dapat beragam mengikuti sistem kalender bulan juga mempengaruhi kegiatan ekonomi. Efek kalender demikian disebut efek variasi liburan atau holiday variation (Bell dan Hilmer, 1983).

Analisis deret waktu yang memiliki pola variasi kalender memerlukan penanganan khusus. Hal ini dikarenakan analisis deret waktu yang umum digunakan menganggap bahwa setiap hari adalah sama tidak bergantung pada penanggalan kalender. Apabila analisis ini dilakukan pada data yang dipengaruhi variasi kalender maka hasil yang diperoleh menjadi kurang tepat. Beberapa penelitian mengenai analisis deret waktu yang mengandung efek variasi kalender telah dilakukan diantaranya Liu (1986) serta Bell dan Hilmer (1983).

Indonesia sebagai negara yang mayoritas beragama Islam, menggunakan kalender Hijriyah untuk menentukan hari besar agama seperti hari raya Idul Fitri (Lebaran). Variasi kalender yang disebabkan hari besar ini merupakan satu contoh efek variasi liburan. Libur Lebaran mempunyai keunikan tersendiri. Pada libur biasa, umumnya efek liburan terjadi sebelum hari libur tersebut terjadi. Namun, pada libur Lebaran efek liburan terjadi sekitar tujuh hari sebelum dan tujuh hari setelah hari Lebaran. Karena itu, pembentukan model deret waktu dengan metode variasi kalender yang mengandung efek variasi liburan, khususnya karena hari Lebaran merupakan suatu hal yang menarik untuk dikaji.

Tujuan dari penelitian ini adalah mengkaji pemodelan deret waktu metode variasi kalender dengan memasukkan efek variasi liburan akibat hari Lebaran. Hasil ini diharapkan dapat dijadikan acuan dasar untuk mempelajari metode variasi kalender lebih lanjut, misalnya dengan menambahkan efek variasi hari perdagangan dan efek variasi liburan pada model variasi kalender.

\section{METODE PENELITIAN}

Pemodelan diawali dengan menentukan variabel yang mewakili variasi kalender dan melakukan pemodelan regresi, menaksir serta menguji parameternya. Kemudian dilanjutkan dengan mengidentifikasi keberadaan sifat 
white noise pada sisaan regresi, jika belum white noise dilanjutkan ke pemodelan ARIMA. Tahap selanjutnya menaksir parameter model variasi kalender yaitu gabungan model regresi dan ARIMA, kemudian menguji kesignifikanannya. Tahap akhir dilakukan dengan memeriksa kesesuaian model dengan asumsi pada sisaan. Pada penelitian ini data yang digunakan yaitu jumlah penumpang kereta api DAOP V Purwokerto dari Januari 2006 sampai Desember 2010.

\section{HASIL DAN PEMBAHASAN}

\subsection{Bentuk Dasar Model Variasi Kalender}

Menurut Bell dan Hilmer (1983), deret waktu $Z_{t}$ yang mengandung variasi kalender dapat dinyatakan sebagai

$$
Z_{t}=f\left(\mathbf{X}_{t} ; \xi\right)+N_{t}
$$

dengan $f\left(\mathbf{X}_{t} ; \boldsymbol{\xi}\right)$ adalah fungsi dari vektor parameter $\boldsymbol{\xi}$ dan vektor $\mathbf{X}_{t}$ yang terdiri dari variabel-variabel bebas yang diamati saat $t$, sedangkan $N_{t}$ merupakan proses stokastik yang disebut gangguan atau noise. Jika $N_{t}$ bukan white noise, maka $N_{t}$ belum tentu stasioner dan dapat dipandang sebagai model ARIMA $(p, d, q)$ yaitu

$$
\begin{array}{r}
\phi_{p}(B)(1-B)^{d} N_{t}=\theta_{q}(B) a_{t} \\
N_{t}=\frac{\theta_{q}(B) a_{t}}{\phi_{p}(B)(1-B)^{d}}
\end{array}
$$

dengan merupakan operator mundur $\left(B^{k} N_{t}=N_{t-k}\right)$, $\phi_{p}(B)=1-\phi_{1} B-\ldots-\phi_{p} B^{p}, \quad \theta_{q}(B)=1-\theta_{1} B-\ldots-\theta_{q} B^{q}, \quad(1-B)^{d}$ merupakan operator diferensi dan $a_{t}$ merupakan barisan variabel acak IID dengan rata-rata 0 dan variansi $\sigma^{2}$.

\subsection{Fungsi Efek Variasi Liburan}

Pada persamaan (1), fungsi $f\left(\mathbf{X}_{t} ; \boldsymbol{\xi}\right)$ dapat dianggap sebagai model regresi yang memuat efek variasi kalender. Apabila efek yang berpengaruh terhadap 
variasi kalender hanya efek liburan, maka fungsi $f\left(\mathbf{X}_{t} ; \xi\right)$ disebut fungsi efek variasi liburan, dinotasikan dengan $L_{t}$, sehingga model variasi kalender pada persamaan (1) dapat dinyatakan sebagai

$$
Z_{t}=L_{t}+N_{t} \text {. }
$$

Pada penelitian ini akan dibahas cara mengkonstruksi fungsi efek variasi liburan $L_{t}$ akibat hari Lebaran untuk dua kasus. Pertama, jika efek Lebaran hanya terjadi selama 7 hari sebelum hari Lebaran dan kedua jika efek Lebaran terjadi selama 7 hari sebelum dan 7 hari setelah hari Lebaran.

\subsubsection{Fungsi Efek Variasi Liburan Sebelum Hari Lebaran}

Penentuan fungsi efek variasi liburan sebelum hari Lebaran dapat diadaptasi dari Bell dan Hilmer (1983) yang membahas efek variasi liburan pada hari libur Paskah. Pada model ini diasumsikan satuan waktu dari deret waktu adalah bulan. Misal $\tau$ menyatakan banyaknya hari sebelum hari Lebaran dan $\tilde{\alpha}_{i}$ menyatakan efek liburan pada hari ke- $i$ sebelum hari Lebaran. Jika $\tilde{\alpha}_{i}$ diasumsikan sama untuk hari ke- $i=1,2, \ldots, \tau$ dan didefinisikan 0 untuk lainnya maka total efek libur Lebaran dapat ditulis

$$
\omega=\tilde{\alpha}_{1}+\ldots+\tilde{\alpha}_{\tau}=\tilde{\alpha} \tau .
$$

Fungsi efek variasi liburan pada bulan ke- $t$ dapat dinyatakan sebagai

$$
L_{t}=\omega H(\tau, t)
$$

dengan $H(\tau, t)$ menyatakan proporsi periode waktu $\tau$ hari sebelum hari Lebaran pada bulan $t$, atau

$$
H(\tau, t)=\frac{1}{\tau} \sum_{i=1}^{\tau} h(i, t)
$$

dan $h(i, t)$ merupakan fungsi indikator yang bernilai 1 ketika hari ke- $i$ sebelum hari libur jatuh pada bulan $t$ dan bernilai 0 untuk lainnya.

\subsubsection{Fungsi Efek Variasi Liburan Sebelum dan Setelah Hari Lebaran}

Pada bagian ini fungsi efek variasi liburan akan dimodifikasi dengan menambahkan efek hari setelah hari Lebaran. Misalkan $\tau^{-}$menyatakan 
banyaknya hari sebelum hari Lebaran dan $\tau^{+}$menyatakan banyaknya hari setelah hari Lebaran. Pola untuk efek liburan $\tilde{\alpha}_{i}$ didefinisikan sebagai

$$
\tilde{\alpha}_{i}= \begin{cases}\tilde{\alpha}, & i=1^{-}, 2^{-}, \ldots, \tau^{-} \text {dan } i=1^{+}, 2^{+}, \ldots, \tau^{+} \\ 0, & \text { lainnya },\end{cases}
$$

maka total efek selama $\tau^{-}$hari sebelum hari Lebaran dan $\tau^{+}$hari setelah hari Lebaran dapat dituliskan sebagai

$$
\omega=\tilde{\alpha}\left(\tau^{-}+\tau^{+}\right) .
$$

Fungsi efek variasi liburan saat $t$ dapat dituliskan sebagai

$$
L_{t}=\omega H\left(\tau^{-}, \tau^{+} ; t\right)
$$

dengan $H\left(\tau^{-}, \tau^{+} ; t\right)$ menyatakan proporsi periode waktu $\tau^{-}$hari sebelum dan $\tau^{+}$ hari setelah hari Lebaran pada bulan $t$, yang dapat dinyatakan sebagai

$$
H\left(\tau^{-}, \tau^{+} ; t\right)=\frac{1}{\tau^{-}+\tau^{+}}\left[\sum_{i=1}^{\tau^{-}} h(i, t)+\sum_{i=1}^{\tau^{+}} h(i, t)\right] .
$$

\subsection{Contoh Aplikasi Pemodelan}

Berikut contoh pemodelan metode variasi kalender dengan memasukkan efek variasi liburan akibat hari Lebaran pada data jumlah penumpang kereta api DAOP V Purwokerto. Berdasarkan Gambar 1 terlihat bahwa pada bulan-bulan yang bertepatan dengan libur Lebaran terjadi peningkatan jumlah penumpang yang cukup tinggi dibanding dengan bulan-bulan yang lain. Lonjakan penumpang pada bulan terjadinya Lebaran terjadi karena adanya budaya mudik yang dilakukan oleh masyarakat selama periode libur Lebaran. Oleh karena itu, cukup beralasan jika data jumlah penumpang kereta api dimodelkan dengan metode variasi kalender dengan efek libur Lebaran yang berpengaruh diasumsikan terjadi pada 7 hari sebelum dan 7 hari sesudah hari Lebaran. Model regresi yang terbentuk adalah

$$
Z_{t}=230180+95082 H\left(7^{-}, 7^{+} ; t\right)+N_{t}
$$




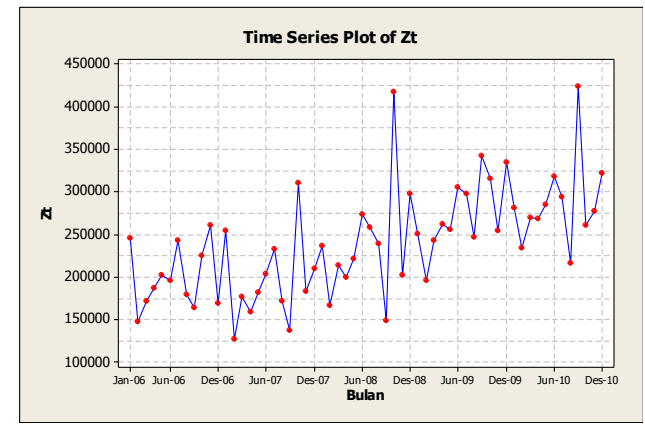

Gambar 1. Time Series Plot Jumlah Penumpang Kereta Api

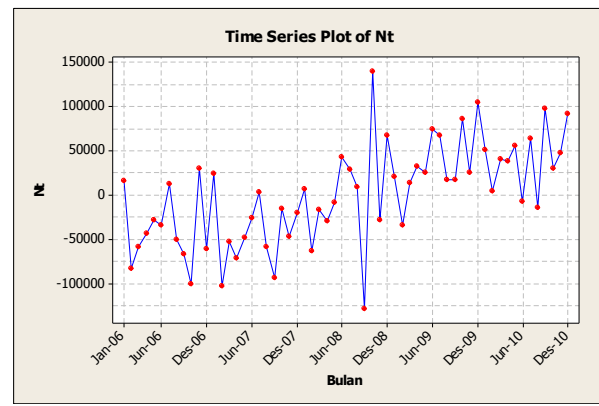

Gambar 2. Plot Deret Waktu $N_{t}$

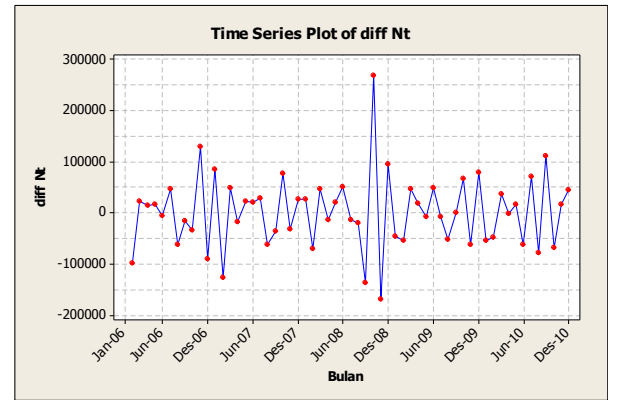

Gambar 3. Plot Hasil Diferensi $N_{t}$

Selanjutnya yaitu pengujian asumsi sisaan regresi $N_{t}$. Ketidakstasioneran pada $N_{t}$ dapat diatasi dengan proses diferensi. Berdasarkan plot hasil diferensi $N_{t}$ pada Gambar 3, maka $N_{t}$ dapat dikatakan telah stasioner. Langkah selanjutnya yaitu mengidentifikasi plot FAK dan FAKP untuk menentukan orde dari AR dan MA.
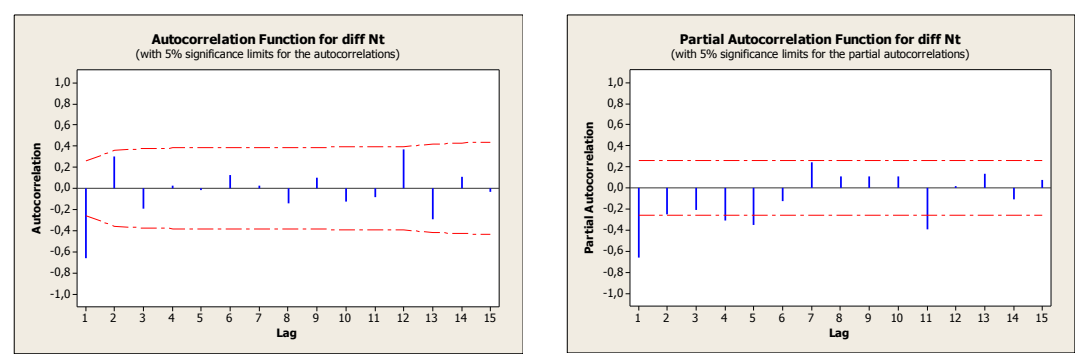

Gambar 4. Plot FAK dan FAKP Hasil Diferensi $N_{t}$ 
Berdasarkan Gambar 4, model dugaannya yaitu:

a. Model Gabungan ARIMA $(1,1,0)$ dan $H\left(7^{-}, 7^{+} ; t\right)$

Pada Tabel 1, parameter $\omega_{0}$ menunjukkan tidak signifikan karena $p$-value $>\alpha=0,05$. Oleh karena itu, parameter konstanta perlu dikeluarkan dari model sehingga model dugaan berubah menjadi gabungan ARIMA $(1,1,0)$, tanpa konstanta dan $H\left(7^{-}, 7^{+} ; t\right)$. Hasil penaksiran Tabel 2 menunjukkan semua parameter telah signifikan karena $p$-value $<\alpha=0,05$. Langkah selanjutnya yaitu pengujian asumsi sisaan dari model variasi kalender. Berdasarkan Tabel 3 diperoleh $p$-value untuk lag 6, 12, 18, dan 24 kurang dari $\alpha=0,05$, maka sisaan tidak white noise, sehingga model dugaan tidak dapat digunakan.

Tabel 1. Hasil Taksiran Parameter Model Gabungan ARIMA $(1,1,0)$ dan $H\left(7^{-}, 7^{+} ; t\right)$

\begin{tabular}{|c|c|c|c|}
\hline Parameter & Taksiran & $t_{\text {hitung }}$ & $p$-value \\
\hline$\omega_{0}$ & $-7160,7$ & $-1,47$ & 0,1460 \\
\hline$\omega_{1}$ & 100044,5 & 4,23 & $<0,0001$ \\
\hline$\phi_{1}$ & $-0,64419$ & $-6,24$ & $<0,0001$ \\
\hline
\end{tabular}

Tabel 2. Hasil Taksiran Parameter Model Gabungan ARIMA $(1,1,0)$, Tanpa Konstanta dan $H\left(7^{-}, 7^{+} ; t\right)$

\begin{tabular}{|c|c|c|c|}
\hline Parameter & Taksiran & $t_{\text {hitung }}$ & $p$-value \\
\hline$\omega_{1}$ & 85722,6 & 3,94 & $<0,0002$ \\
\hline$\phi_{1}$ & $-0,63980$ & $-6,23$ & $<0,0001$ \\
\hline
\end{tabular}

Tabel 3. Hasil Uji White Noise Model Gabungan ARIMA $(1,1,0)$, Tanpa Konstanta dan $H\left(7^{-}, 7^{+} ; t\right)$

\begin{tabular}{|c|c|}
\hline Lag & $p$-value \\
\hline 6 & 0,0096 \\
\hline 12 & $<0,0001$ \\
\hline 18 & $<0,0001$ \\
\hline 24 & $<0,0001$ \\
\hline
\end{tabular}


b. Model Gabungan ARIMA $(0,1,1)$ dan $H\left(7^{-}, 7^{+} ; t\right)$

Hasil taksiran parameter model pada Tabel 4 menunjukkan bahwa semua parameter model signifikan karena $p$-value $<\alpha=0,05$. Langkah selanjutnya yaitu pengujian asumsi sisaan model. Pada Tabel 5, p-value untuk lag 12, 18, dan 24 kurang dari $\alpha=0,05$, maka disimpulkan sisaan tidak white noise, akibatnya model dugaan tidak dapat digunakan.

c. Model Gabungan ARIMA $(1,1,1)$ dan $H\left(7^{-}, 7^{+} ; t\right)$

Hasil taksiran parameter model pada Tabel 6 menunjukkan bahwa parameter $\omega_{0}$ tidak signifikan. Hal ini dikarenakan $p$-value $>\alpha=0,05$, akibatnya parameter konstanta perlu dikeluarkan dari model. Model dugaan variasi kalender berubah menjadi gabungan $\operatorname{ARIMA}(1,1,1)$, tanpa konstanta dan $H\left(7^{-}, 7^{+} ; t\right)$. Berdasarkan Tabel 7 , semua parameter model signifikan karena $p-$ value $<\alpha=0,05$. Langkah selanjutnya yaitu pengujian asumsi sisaan yang ditampilkan pada Tabel 8. Untuk lag 12, 18, dan 24, p-value yang diperoleh kurang dari $\alpha=0,05$, maka sisaan model tidak white noise akibatnya model dugaan tidak dapat digunakan.

Tabel 4. Hasil Taksiran Parameter Model Gabungan ARIMA $(0,1,1)$ dan $H\left(7^{-}, 7^{+} ; t\right)$

\begin{tabular}{|c|c|c|c|}
\hline Parameter & Taksiran & $t_{\text {hitung }}$ & $p$-value \\
\hline$\omega_{0}$ & $-4435,2$ & $-2,04$ & 0,0458 \\
\hline$\omega_{1}$ & 70060,3 & 3,05 & 0,0035 \\
\hline$\theta_{1}$ & 0,87710 & 13,16 & $<0,0001$ \\
\hline
\end{tabular}

Tabel 5. Hasil Uji White Noise Model Gabungan ARIMA $(0,1,1)$ dan $H\left(7^{-}, 7^{+} ; t\right)$

\begin{tabular}{|c|c|}
\hline Lag & $p$-value \\
\hline 6 & 0,2029 \\
\hline 12 & 0,0009 \\
\hline 18 & 0,0011 \\
\hline 24 & $<0,0001$ \\
\hline
\end{tabular}


Tabel 6. Hasil Taksiran Parameter Model Gabungan ARIMA $(1,1,1)$ dan $H\left(7^{-}, 7^{+} ; t\right)$

\begin{tabular}{|c|c|c|c|}
\hline Parameter & Taksiran & $t_{\text {hitung }}$ & $p$-value \\
\hline$\omega_{0}$ & $-2918,0$ & $-1,44$ & 0,1557 \\
\hline$\omega_{1}$ & 51750,0 & 2,62 & 0,0114 \\
\hline$\theta_{1}$ & 0,79363 & 7,89 & $<0,0001$ \\
\hline$\phi_{1}$ & $-0,30860$ & $-2,06$ & 0,0446 \\
\hline
\end{tabular}

Tabel 7. Hasil Taksiran Parameter Model Gabungan ARIMA $(1,1,1)$, Tanpa Konstanta dan $H\left(7^{-}, 7^{+} ; t\right)$

\begin{tabular}{|c|c|c|c|}
\hline Parameter & Taksiran & $t_{\text {hitung }}$ & $p$-value \\
\hline$\omega_{1}$ & 30318,5 & 2,66 & 0,0102 \\
\hline$\theta_{1}$ & 0,76033 & 7,58 & $<0,0001$ \\
\hline$\phi_{1}$ & $-0,34513$ & $-2,40$ & 0,0197 \\
\hline
\end{tabular}

Tabel 8. Hasil Uji White Noise Model Gabungan ARIMA $(1,1,1)$, tanpa konstanta dan $H\left(7^{-}, 7^{+} ; t\right)$

\begin{tabular}{|c|c|}
\hline Lag & $p$-value \\
\hline 6 & 0,4086 \\
\hline 12 & 0,0003 \\
\hline 18 & 0,0008 \\
\hline 24 & $<0,0001$ \\
\hline
\end{tabular}

Berdasarkan hasil pengujian untuk ketiga kemungkinan model menunjukkan bahwa model dugaan tidak dapat digunakan karena tidak memenuhi syarat. Kemungkinan lain untuk mendapatkan model yang lebih baik yaitu digunakan model ARIMA musiman. Hal ini dikarenakan data jumlah penumpang berupa data bulanan yang mengindikasikan adanya pola musiman. Berdasarkan Gambar 4, kemungkinan lain model dugaan variasi kalender adalah gabungan ARIMA $(1,1,1)(0,0,1)^{12}$ dan $H\left(7^{-}, 7^{+} ; t\right)$. Hasil taksiran parameter model dugaan pada Tabel 9 menunjukkan parameter $\omega_{0}$ paling tidak signifikan dibandingkan 
parameter yang lain. Hal ini dikarenakan $p$-value $>\alpha=0,05$ sehingga parameter konstanta perlu dikeluarkan dari model.

Tabel 9. Hasil Taksiran Parameter Model Gabungan ARIMA $(1,1,1)(0,0,1)^{12}$ dan $H\left(7^{-}, 7^{+} ; t\right)$

\begin{tabular}{|c|c|c|c|}
\hline Parameter & Taksiran & $t_{\text {hitung }}$ & $p$-value \\
\hline$\omega_{0}$ & $-3766,0$ & $-1,73$ & 0,0885 \\
\hline$\omega_{1}$ & 59938,7 & 2,88 & 0,0058 \\
\hline$\theta_{1}$ & 0,82182 & 8,88 & $<0,0001$ \\
\hline$\Theta_{1}$ & $-0,78260$ & $-7,11$ & $<0,001$ \\
\hline$\phi_{1}$ & $-0,29231$ & $-1,92$ & 0,0596 \\
\hline
\end{tabular}

Tabel 10. Hasil Taksiran Parameter Model Gabungan ARIMA $(1,1,1)(0,0,1)^{12}$, Tanpa Konstanta dan $H\left(7^{-}, 7^{+} ; t\right)$

\begin{tabular}{|c|c|c|c|}
\hline Parameter & Taksiran & $t_{\text {hitung }}$ & $p$-value \\
\hline$\omega_{1}$ & 33344,9 & 2,51 & 0,0150 \\
\hline$\theta_{1}$ & 0,76395 & 7,40 & $<0,0001$ \\
\hline$\Theta_{1}$ & $-0,76335$ & $-6,95$ & $<0,0001$ \\
\hline$\phi_{1}$ & $-0,33724$ & $-2,28$ & 0,0264 \\
\hline
\end{tabular}

Tabel 11. Hasil Uji White Noise Model Gabungan ARIMA $(1,1,1)(0,0,1)^{12}$, Tanpa Konstanta dan $H\left(7^{-}, 7^{+} ; t\right)$

\begin{tabular}{|c|c|}
\hline Lag & p-value \\
\hline 6 & 0,6688 \\
\hline 12 & 0,9020 \\
\hline 18 & 0,9328 \\
\hline 24 & 0,2072 \\
\hline
\end{tabular}

Selanjutnya, model dugaan variasi kalender berubah menjadi gabungan ARIMA $(1,1,1)(0,0,1)^{12}$, tanpa konstanta dan $H\left(7^{-}, 7^{+} ; t\right)$. Berdasarkan Tabel 10, semua parameter model telah signifikan karena $p$-value $<\alpha=0,05$. Langkah selanjutnya yaitu pengujian asumsi sisaan model. Pada Tabel 11 sisaan model dikatakan telah memenuhi asumsi white noise karena p-value untuk lag 6, 12, 18 
dan 24 kurang dari $\alpha=0,05$. Asumsi kenormalan dilakukan dengan uji Kolmogorov-Smirnov diperoleh $p$-value yaitu $>0,15$, sehingga sisaan dikatakan berdistribusi normal. Karena semua parameter model signifikan, sisaannya memenuhi syarat maka model dapat digunakan untuk memodelkan data jumlah penumpang kereta api. Model tersebut dapat dituliskan sebagai

$$
Z_{t}=\omega_{1} H\left(7^{-}, 7^{+} ; t\right)+\frac{\left(1-\theta_{1} B\right)\left(1-\Theta_{1} B^{12}\right)}{(1-B)\left(1-\phi_{1} B\right)} a_{t} .
$$

Dengan mensubstitusikan nilai-nilai taksiran parameter pada Tabel 10 diperoleh

$$
\begin{aligned}
Z_{t}= & 33344,9 H\left(7^{-}, 7^{+} ; t\right)-22099,7 H\left(7^{-}, 7^{+} ; t-1\right)+3792,34 H\left(7^{-}, 7^{+} ; t-2\right) \\
& +0,66276 Z_{t-1}+0,33724 Z_{t-2}-0,76395 a_{t-1}+0,76335 a_{t-12} \\
& +0,58316 a_{t-13} .
\end{aligned}
$$

Berdasarkan persamaan (10), maka dapat disimpulkan bahwa jumlah penumpang kereta api DAOP V Purwokerto tiap bulannya dipengaruhi oleh proporsi periode waktu 7 hari sebelum dan 7 hari setelah hari Lebaran pada bulan tersebut serta satu dan dua bulan sebelumnya. Selain itu, jumlah penumpang juga dipengaruhi oleh jumlah penumpang pada satu dan dua bulan sebelumnya, serta dipengaruhi oleh sisaan dari model pada satu, dua belas dan tiga belas bulan sebelumnya.

\section{KESIMPULAN DAN SARAN}

Berdasarkan hasil di atas dapat diberikan kesimpulan sebagai berikut:

1. Fungsi efek variasi liburan yang dipengaruhi $\tau^{-}$hari sebelum dan $\tau^{+}$hari setelah hari libur Lebaran dapat dituliskan sebagai

$$
L_{t}=\omega H\left(\tau^{-}, \tau^{+} ; t\right)
$$

dengan $\omega=\tilde{\alpha}\left(\tau^{-}+\tau^{+}\right)$dan $H\left(\tau^{-}, \tau^{+} ; t\right)=\frac{1}{\tau^{-}+\tau^{+}}\left[\sum_{i=1}^{\tau^{-}} h(i, t)+\sum_{i=1}^{\tau^{+}} h(i, t)\right]$.

2. Pada contoh kasus data jumlah penumpang kereta api DAOP V Purwokerto, model variasi kalender yang diperoleh adalah

$$
\begin{aligned}
Z_{t}= & 33344,9 H\left(7^{-}, 7^{+} ; t\right)-22099,7 H\left(7^{-}, 7^{+} ; t-1\right)+3792,34 H\left(7^{-}, 7^{+} ; t-2\right) \\
& +0,66276 Z_{t-1}+0,33724 Z_{t-2}-0,76395 a_{t-1}+0,76335 a_{t-12} \\
& +0,58316 a_{t-13} .
\end{aligned}
$$


Saran yang dapat diberikan pada penelitian ini yaitu pemodelan variasi kalender dapat diperluas dengan menambahkan efek variasi hari perdagangan serta efek variasi liburan dalam model variasi kalender.

\section{UCAPAN TERIMAKASIH}

Artikel ini adalah hasil penelitian skripsi penulis pertama Dr. Nunung Nurhayati.

\section{DAFTAR PUSTAKA}

Aswi dan Sukarna, (2006). Analisis Deret Waktu: Teori dan Aplikasi. Andira Publisher: Makasar.

Bell, W. R. dan Hilmer, S., (1983). Modelling Time Series With Calendar Variation. Journal of American Statistical Association, 78, 526-534.

Liu, L. M., (1986). Identification of Time Series Models in The Presence of Calendar Variation. International Journal of Forecasting, 2, 357-372.

Wei, W. W. S., (2006). Time Series Analysis: Univariate and Multivariate Methods, $2^{\text {nd }}$ Edition. Addison Wesley: Canada. 